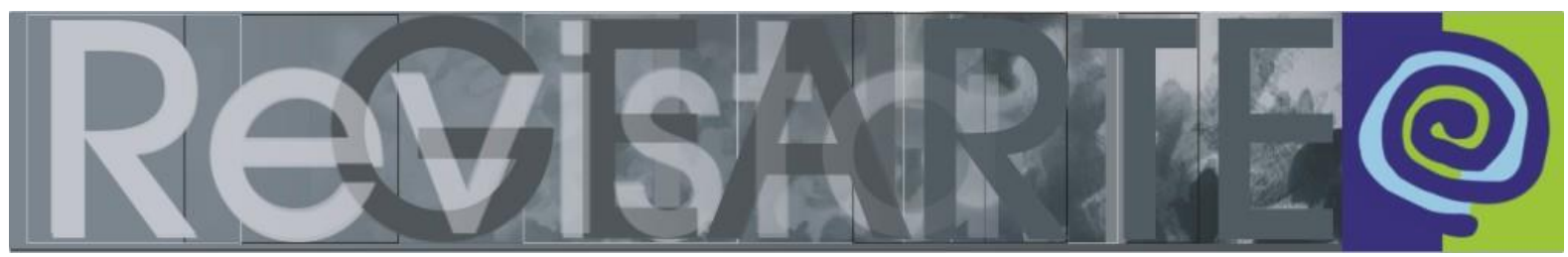

ISSN 2357-9854

\title{
Ensino da Arte: um exercício de reflexão e escrita de si
}

Ursula Rosa da Silva (Universidade Federal de Pelotas — UFPel, Pelotas/RS, Brasil)

RESUMO - Ensino da Arte: um exercício de reflexão e escrita de si - O presente texto trata de uma reflexão a respeito do ensino da arte na universidade, considerando a perspectiva de autoformação docente e de uma escrita de si. O estudo tem como fonte de análise documentos e dados decorrentes do projeto de pesquisa Revisitando o Instituto de Letras e Artes (ILA-1969-2010), que objetiva contextualizar historicamente e valorizar as histórias de vida e de ensino dos docentes dos cursos de artes da Universidade Federal de Pelotas. A pesquisa utiliza como aporte teórico pensadores como Bourdieu e Josso, valorizando a abordagem da escrita de si e elementos que configuram o meio acadêmicos, que influenciam as metodologias de ensino. O texto apresenta uma análise do acervo pessoal de documentos da professora Myriam Anselmo, que atuou no Instituto de Letras e Artes até 1990.

PALAVRAS-CHAVE

Ensino de Arte. Escrita de Si. Formação Docente. Ensino Superior.

RESUMEN - Enseñanza del Arte: un ejercicio de reflexión y escritura propia - Este artículo es una reflexión sobre la enseñanza del arte en la universidad, teniendo en cuenta la perspectiva de la autoformación del profesor y de una escrita propia. El estudio tiene como fuente de análisis los documentos y los datos resultantes del proyecto de investigación Revisitando el Instituto de las Artes y las Letras (ILA - 1969-2010), que tiene como objetivo contextualizar históricamente y valorizar las historias de vida y de la enseñanza de los profesores de los cursos de artes de la Universidad Federal de Pelotas. La investigación utiliza teóricos como Bourdieu y Josso, valorando el método de escrita propia y los elementos que conforman los medios académicos, que influyen en las metodologías de enseñanza. El artículo presenta un análisis de la colección personal de documentos de la profesora Myriam Anselmo que trabajo en el Instituto de Artes y Letras hasta 1990.

PALABRAS CLAVE

Enseñanza del Arte. La Escritura Propia. Formación del Profesorado. Enseñanza Superior.

Aquele foi o dia. Na verdade, era uma noite de inverno, o saguão da universidade, onde eu estudava, estava cheio. Havia um burburinho de vozes. $\mathrm{O}$ entrar e sair de pessoas. O movimento na livraria, pessoas se direcionando para as salas de aula. Sorrisos, olhares, conversas animadas. Alguns alunos expondo imagens no chão para apreciação. Ao entrar naquele lugar, mais uma entre tantas outras noites de aula, fui levada para um instante existencial, fui puxada pelo tempo a olhar para a minha existência. Sei que foi naquele momento que decidi ser professora. Não foi uma escolha, foi um arrebatamento. Senti que meu lugar seria ali no meio deste movimento constante de busca por conhecimento, de trocas e entrelaçamento 
de experiências, de dúvidas, de incertezas, mas pulsante: a vida acadêmica. Senti que, a partir de então, o roteiro seria escrito por mim.

Como nos diz Bergson (2006, p. 49) "jamais atingiremos o passado sem nos colocarmos nele de saída". Refletindo sobre algumas especificidades e nas transformações do ensino superior, vejo como inevitável estabelecer relações com a memória.

Numa época (fins dos anos 1980) em que os cursos de Licenciatura, ou seja, aqueles que preparam professores, não tratavam diretamente da questão de como realizar o ensino na escola, não se falava da tal transposição didática, nem de como seríamos ou o que faríamos, na escola, ao nos tornar docentes. As disciplinas pedagógicas da maioria das Licenciaturas (didáticas; estrutura do ensino; currículos e normas, etc.) eram oferecidas, em geral, pelos cursos de Pedagogia e não por professores dos próprios cursos de licenciatura. Somente em meados dos anos 1990 é que se começa a debater sobre as características do ensino na escola e de como os professores devem estar preparados desde sua formação na universidade. Tais movimentos acadêmico-sociais, fortalecidos por mudanças pedagógicas fundamentais para o ensino, podemos citar as influências de Matthew Lipmann (1990), com sua filosofia para crianças, e, na arte, a Abordagem Triangular, nos estudos de Ana Mae Barbosa (1986; 1991), por exemplo, como também a retomada de estudo em autores como Rousseau, Dewey, Paulo Freire, contribuíram para o crescimento e a necessidade da filosofia e da arte na escola, dois campos de saber com os quais trabalho e a partir dos quais compreendo o acontecer do conhecimento.

É a mesma experiência de formação transformadora que busco encontrar em nos professores, a partir da pesquisa que desenvolvo no projeto: Revisitando o Instituto de Letras de $\operatorname{Artes}^{1}$ (1969-2010), em que abordo o trabalho dos docentes que

\footnotetext{
1 Em 1969, a Universidade Federal de Pelotas originou-se da fusão da antiga Universidade Federal Rural do Rio Grande do Sul com entidades isoladas de ensino superior, em atividade no Município, como a Faculdade de Agronomia "Eliseu Maciel" - a primeira fundada no Brasil - a Faculdade de Odontologia, a Faculdade de Direito, as faculdades de Ciências Domésticas e de Medicina Veterinária, o Instituto de Sociologia e Política e a Faculdade de Medicina de Pelotas. Além destas, o Conservatório de Música de Pelotas e a Escola de Belas Artes Cármen Trápaga Simões (E.B.A., criada em 1949) passam a ser unidades agregadas à UFPel. O primeiro Reitor da UFPel foi o Prof. Delfim Mendes Silveira, que administrou a Universidade até 1977. Os Cursos de Artes da UFPel/RS
} 
passaram, e que ainda estão, no atual Centro de Artes da Universidade Federal de Pelotas (RS). A memória do trabalho, das vivências e das realizações dos professores é um dos enfoques que pretendo trazer à tona, considerando que este Centro é formador de profissionais que atuam, na sua maioria, no Sul do Brasil desde os anos 1970. Além do aspecto de historiografar os momentos vividos no ILA, este estudo pretende retomar a produção dos professores no sentido de dar ênfase as suas concepções pedagógicas dentro do ensino superior, sua visão do que significa o ensino de arte, quais as metodologias e procedimentos para efetivá-lo na formação tanto de artistas quanto de professores de artes, e se este ensino nos aponta especificidades nas visualidades produzidas.

Nesse sentido, penso que as pesquisas e ensaios escritos por professores do Centro de Artes podem dar um panorama das características deste ensino no período de 1969 a 2010, bem como podemos perceber que as mudanças nacionais, em termos de reformas educacionais e curriculares, têm uma relação direta com o modo como os cursos vão se desenhando ao longo da história e produzindo visualidades que também permitam identificá-lo como formador do campo da arte na região Sul do RS.

A história do Centro de Artes passou por várias transformações e denominações - Escola de Belas Artes Carmen Trápaga Simões (1949), Instituto de Artes (1971), Instituto de Letras e Artes (de 1973 a 2005), e Instituto de Artes e Design (de 2005 a 2010) - e o cotidiano desta memória ainda tem poucos registros em textos com o enfoque da historiografia.

tiveram sua origem na Escola de Belas Artes (EBA), que obteve autorização do Governo Federal para funcionamento dos Cursos de Graduação em Pintura, Escultura e Gravura em dezembro de 1955 (Decreto $n^{\circ}$ 37690). Em 1967, com o recebimento de um prédio próprio, a Escola passou a chamar-se Escola de Belas Artes Dona Carmen Trápaga Simões (EBA) e, com a criação da Universidade Federal de Pelotas em 1969, tornou-se unidade agregada. O estatuto da UFPel, de 1969, criou cinco Institutos básicos: Instituto de Artes; Instituto de Biologia; Instituto de Ciências Humanas; Instituto de Física e Matemática e Instituto de Química e Geociências. Em 1973, o Conselho Técnico-administrativo da EBA dá andamento ao processo de transferência do patrimônio da unidade agregada (EBA), aprovando a incorporação da Escola à Universidade, com a condição de que os professores e os funcionários fossem transferidos para o quadro da UFPel. A união da EBA com o Instituto de Artes deu origem ao ILA (Instituto de Letras e Artes da UFPel). Dados conforme Arquivo do Centro de Artes. UFPel, Pelotas. 
No ano de 2012, dando sequência a uma série de atividades para retomar a história do ILA - Instituto de Letras e Artes (atual Centro de Artes) da Universidade Federal de Pelotas (UFPel), convidamos um grupo de professores aposentados para conversar com alunos e professores a respeito de suas memórias como docentes da UFPel, suas estratégias como gestores e de suas metodologias de ensino no campo da arte. Este encontro foi denominado Seminário Memórias do Ensino da Arte. Os relatos foram registrados em vídeo e, no ano de 2014, parte da pesquisa sobre a história do ensino de arte na UFPel foi documentada².

Na oportunidade do Seminário de 2012, a professora Myriam Anselmo ${ }^{3}$ doou para esta pesquisa alguns de seus documentos, dentre textos; imagens; cadernos de aula. Este gesto de passar seus registros significou muito mais do que uma entrega de papéis ou de um acervo que pode manter uma memória: significou uma entrega de si, uma aposta na continuidade de uma luta de anos pelo ensino e dedicação às artes, que iniciou, como ela disse: "com um contrato de serviço sem remuneração, com prazo indeterminado" ${ }^{4}$, apostando que a universidade iria criar um Instituto de Artes. Os onze professores que começaram a dar aulas na criação deste Instituto pela Universidade, trabalhando literalmente por amor, deram muito de si para estruturar o ensino das artes dentro da UFPel.

As memórias da docência estão, em geral, ligadas a aspectos biográficos, ou seja, quando se fala de uma metodologia aplicada por professores, também é preciso considerar o modo como estes professores se formaram, como vêem o mundo, quais as suas expectativas no campo do ensino, enfim, a pessoa que ensina é parte do processo de ensino, e suas escolhas estão, a todo o momento, influenciando seu

2 Um vídeo documentário foi produzido por professores e alunos do Curso de Cinema da UFPel, sob coordenação da profa. Cintia Langie, e como resultado parcial da pesquisa orientada pela autora deste texto. O documentário encontra-se disponível em: <http://paeufpel.blogspot.com.br/2014/06/centro-deartes-origens.html>.

3 Myriam de Souza Anselmo ingressou em agosto de 1968 na Escola de Belas Artes (EBA) para lecionar Anatomia Artística. Depois a partir da criação da UFPel, em 1969, e a união da EBA com o Instituto de Artes, que deu origem ao Instituto de Letras e Artes (ILA), neste foi professora de anatomia e escultura, foi chefe do Departamento de Artes Visuais, em 1975, coordenou o Curso de Graduação em Pintura, Escultura e Gravura em 1973, foi diretora do Instituto de Letras e Artes de 1977 a 1981, aposentou-se em 1990.

4 Relato oral de Myriam de Souza Anselmo no Seminário Memórias do Ensino da Arte, Centro de Artes, 2012. 
modo de agir e sua atuação como docente e como formador. Além da evidenciação da memória no processo de reconhecimento desta constituição da formação, a reflexão sobre a autoformação está presente neste desenvolvimento de uma escrita de si e são, conforme Josso (2010, p. 35), "aprendizagens experienciais a partir do que nos dizem as narrativas de formação que servem de material para compreender os processos de formação, de conhecimento e de aprendizagem".

A pensadora Marie-Christine Josso, que trabalha com o método biográfico, mostra como as histórias de vida são fundamentais para a constituição do processo de formação. Na obra Experiências de Vida e Formação, ela apresenta alguns tópicos que desenvolveu em sua tese de doutoramento (publicada em 1991, com o título Caminhar para Si) e também aborda a importância das histórias de vidas, como material de apoio na investigação sobre formação, principalmente no espaço universitário. Para Josso, o enfoque por histórias de vida tem dois objetivos: evidenciar o modo como o pesquisador modifica seu posicionamento ao se envolver e aprimorar a metodologia de pesquisa-formação vinculada a uma história de vida; e constituir um novo campo de reflexão, abrangendo a formação e a autoformação (2010, p. 31).

A descrição dos processos de formação e de conhecimento, sob a forma de gêneros de saber-fazer e de conhecimento, permite reagrupar o que foi aprendido em termos de transações possíveis consigo mesmo, com o seu ambiente humano [...] e com seu ambiente natural [...]. A narrativa de um percurso intelectual e de práticas de conhecimento põe em evidência os registros da expressão dos desafios de conhecimento ao longo da vida. Esses registros são precisamente os conhecimentos elaborados em função de sensibilidades particulares em um dado período (JOSSO, 2010, p. 40-41).

Por outro lado, também se torna importante avaliar os aspectos da estrutura que a academia possibilita aos professores para que o trabalho pedagógico tenha um apoio, não apenas de base metodológica, curricular e conceitual, como também de âmbito da infra-estrutura, de um espaço que dê condições para que o processo de ensino-aprendizagem se efetive. 
Pierre Bourdieu tem refletido em seus textos a respeito da abordagem didática, bem como a estrutura que está por trás do ensino. Em sua obra Homo Academicus (publicada na França em 1984), ele toma como tema os acontecimentos que ocorreram antes e durante maio de 1968, traçando uma topografia social do mundo universitário, demonstrando que existem dois lados nesta estrutura composta por sujeitos classificadores: o lado do saber, caracterizado pela liberdade acadêmica e, de outro, o lado do poder, que toma para si o que chama de responsabilidade social (BOURDIEU, 2013, p. 17). O autor analisa a sociedade como estruturada em campos, e a universidade, assim como a escola, possuem uma lógica organizacional que compete com o campo do saber, ou seja, ambos acabam dependendo um do outro.

Neste artigo apresento uma parte da pesquisa que trata do encontro com o acervo didático da professora Myriam Anselmo. Nos escritos de Myriam, encontrei desde planos de aula a planejamentos de gestão, que revelam uma organização prática em um cotidiano administrativo, mas também, e muito articulada a um pensamento sobre esta estrutura administrativa, uma elaboração de procedimentos didáticos necessários para a fundamentação do ensino na arte e no âmbito da universidade. Aliás, somente o contato com os cadernos de escrita de Myriam já são fonte de uma experiência de emoção. A escrita é feita à mão, com caneta, muitos desenhos a lápis, e com o cuidado de uma professora que apresenta de forma organizada seu planejamento para cada dia de aula. Esses espaços que se intercalam na escrita testemunham que, na verdade, a estrutura acadêmica não existe separadamente do movimento pedagógico diário da universidade. Esta escrita demonstra um pensar, que é vida pulsante, presente nas linhas traçadas dos currículos, ou seja, que todo o planejamento, que fica no papel e no que chamamos "grade" curricular, deve ser vivido no cotidiano acadêmico. É desta vida que trata a formação.

Ao abrir um dos cadernos ${ }^{5}$, dentro dele estava, como perdida dentre as páginas escritas, uma folha seca, de um verde desbotado, cuja cor, parte de seu verde, tinha passado para a folha de papel, deixando sua marca (imagem 1). Uma pequena folha

5 Caderno de anotações de Myriam Anselmo - com registros de novembro/1980 a dezembro/1982. 
seca no meio de um caderno manuscrito. Uma simples folha, mas com tantos significados, de vivências, de memórias, de mensagens implícitas, deixadas - sem grandes pretensões para o futuro - nas páginas escritas à mão, num caderno de planejamento de aulas, um diário de bordo, revelador de um cotidiano pedagógico e administrativo, cujos temas, problemas e provocações nos aproximam muito do que nós hoje vivenciamos neste cotidiano atual.

Figura 1 - Folha seca em caderno de planos de aula de Myriam Anselmo (texto de 1982)

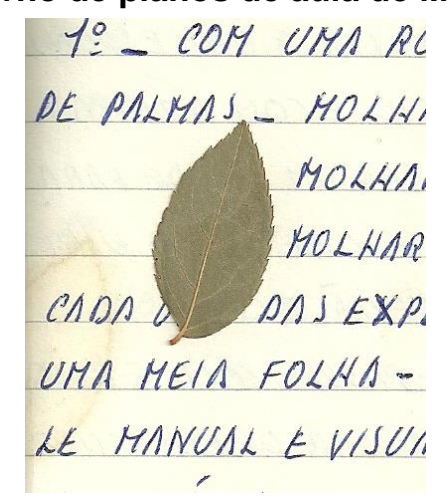

Fonte: Caderno de anotações de Myriam Anselmo.

A primeira impressão foi a de acaso, uma folha que ficou guardada sem intenção. Mas logo percebi que havia um grande sentido naquela folha e que todo um pensamento e planejamentos de aulas foram feitos a partir dela, pois na mesma página estava um texto e uma sequência explicativa que utilizava a folha para exemplificar o ritmo na composição. 
Figura 2 - Folha seca e texto explicativo de como obter o ritmo na composição, em caderno de planos de aula de Myriam Anselmo (texto de 1982)

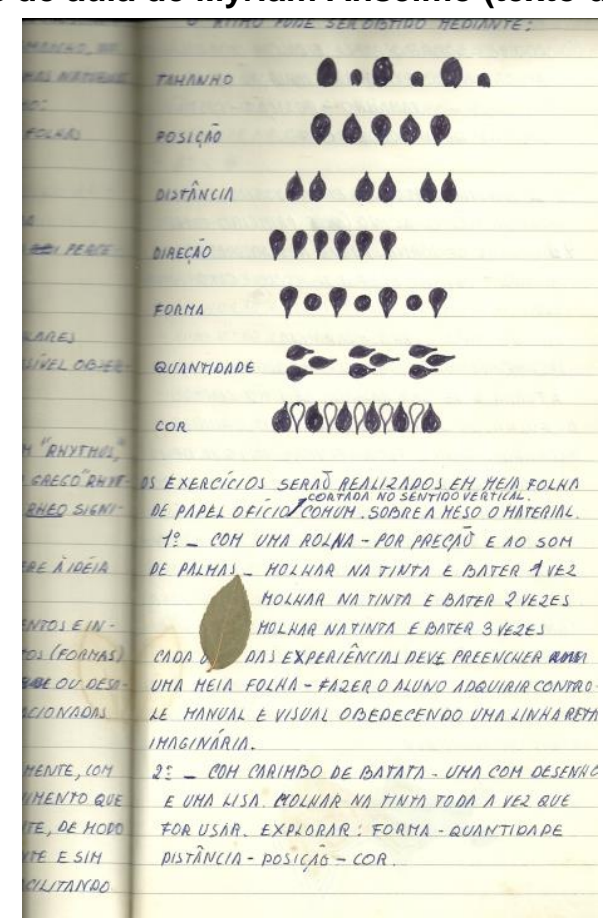

Fonte: Caderno de anotações de Myriam Anselmo.

Além do conteúdo que este caderno traz, começo a refletir a partir dele mesmo, do suporte que envolve uma escrita, uma documentação, uma narrativa muito íntima no sentido de um diário com o qual conversamos e confessamos nossos sonhos e nossas decepções, as realizações, as conquistas e as desilusões também do cotidiano. A escrita à mão nos desloca no tempo, antes do computador, antes do email, das mensagens e textos descartáveis de hoje. A tecnologia nos afastou de certa pessoalidade expressas nestes documentos manuscritos. Também tirou de certo modo a autoria, do traço escrito, da caligrafia, sobreposta pela máquina que digitamos, das impressões que nos distanciam do gesto da escrita e da marca manual no papel. O caderno manuscrito traz uma nostalgia do tempo que guarda consigo.

Ao mergulhar neste documento, vou confirmando algumas considerações: em primeiro lugar, que existe uma estrutura na instituição de ensino da qual não se pode prescindir e que, cotidianamente, temos que enfrentar; segundo, que a base pedagógica está absolutamente ligada à estrutura físico-administrativa da instituição.

A partir disso, pergunto: qual seria o papel do ensino da arte hoje, dentro e fora do espaço acadêmico? Acredito que a formação de professores passa pelo convívio 
cotidiano também do grupo de que fazemos parte, aprendemos com nossos colegas, e isso é o que melhor define a formação continuada: dia a dia continuamos nossa jornada de aprendizagem, num cotidiano que vai dando significado ao nosso fazer. $E$ esse cotidiano, como define Fernando Hernández (2007), demanda que se desenvolva uma percepção aguçada para ver o novo no "mesmo", ou seja, o mundo é o mesmo todos os dias, as pessoas são as mesmas, ou pensam ser, o segredo está em perguntar "quem vê?" e "o que vê?". Aquele que se coloca num estado de predisposição para ver o novo vai sempre buscar outras formas de significação, não vai se acomodar com os significados dados e vividos no dia-a-dia pelo senso comum. Ao contrário, o cotidiano vai ultrapassar o sentido de mesmice para dar-nos novos olhares, outras formas de significar, desde que estejamos prontos para esta abertura para o mundo.

Assim, vejo o legado de Myriam Anselmo como motivador, inspirador de mais fazeres, de mais vida, de mais motivos para seguirmos, darmos continuidade e para contagiar a outros com arte. Dentre suas anotações de compras, consertos e a demanda por verbas para a aquisição de um prédio para o ILA (Instituto de Letras e Artes), as questões pedagógicas sempre aparecem articuladas. Vemos que em seus objetivos para os "próximos dias" está presente a articulação das ações de ensino, pesquisa, extensão junto a equipamentos, material, pessoal e espaço, o que mostra que sempre teve a visão de que a estrutura acadêmica e a base pedagógica devem andar juntas.

\footnotetext{
Dia 01 de julho de 1981 - considerações em face a uma mudança de período letivo e a aquisição do prédio próprio do ILA - Mente - Mentes - Mentalidades - Vinculando a função ao espaço e considerando que para agir é preciso espaço, vejamos as providências cabíveis para a direção nos próximos dias, quanto ao: 1- Ensino; 2- Pesquisa; 3- Extensão; 4- Pessoal; 5- Material, equipamentos; 6- Espaço (Caderno de anotações de Myriam Anselmo nov./1980 a dez./1982).
}

No encaminhamento dos itens citados, Myriam traz um estudo de reestruturação de todos os cursos do ILA, em termos de conteúdo, estrutura e avaliação, e considera as tarefas que compete a um Colegiado de Curso:

Um Colegiado por curso deverá ter condições de: atualizar constantemente o currículo de acordo com o meio; Manter os alunos atualizados com os eventos realizados no país e fora do país; Organizar o preparo, 
acompanhamento e a integração do alunado com os trabalhos com a comunidade através da extensão; Manter-se atento para com o mercado de trabalho aprimorando o nosso aluno - o formado e o em formação propiciando uma constante melhoria através de cursos, seminários, encontros, excursões (...) (Caderno de anotações de Myriam Anselmo, dia 01/07/1981).

Ela propõe, em sua análise do contexto da universidade, que as Graduações dos Cursos de Bacharelado em artes passem a ser constituídos em separado (Pintura; Escultura e Gravura) para que os mesmos se fortaleçam, considerando que Pelotas tem condições e demanda para formar mais artistas e o ILA tem "espaço e gente para implementar o fazer artístico". Em seus estudos, Myriam Anselmo propõe que os cursos de Artes Plásticas tenham uma parte do currículo básico em comum; que cada aluno faça no mínimo uma mostra individual avaliada por docentes e que no fim da Graduação o aluno tenha, pelo menos três trabalhos que caracterizem sua poética, devendo esta produção passar por uma banca de avaliação. Esta proposta, pensada em 1980, está na origem dos atuais TCCs (trabalho de conclusão de curso). Vejo que o TCC é um modo de qualificar a formação do aluno, fazendo-o não apenas elaborar um texto como resultado de pesquisa, mas principalmente faz com que haja um aprendizado no modo de pesquisar, de estudar, de elaborar textos e de expor seu pensamento.

Para criar um elo entre os Cursos e ter um espaço para pensar a relação pedagógica no ILA, Myriam propôs a criação de um Núcleo de Apoio Pedagógico, vinculado aos cursos e departamentos que possa dar acesso a documentos fundamentais da área de artes, de outras universidades brasileiras, bem como orientações de órgãos e instituições que possam dar o apoio nas metodologias de ensino como CAPES, MEC, etc. Este Núcleo seria responsável por pensar a qualidade dos cursos. Ligada ao Núcleo, a Biblioteca setorial devia ser constituída de modo a possibilitar um acervo específico de arte e de qualidade com livros, revistas, periódicos fundamentais ao ensino das artes. A Extensão é pensada como fundamental para a melhoria do ensino, e deve ter sua prática junto à comunidade e às escolas, com oferta constante de atividades artísticas em espaços dentro e fora da UFPel.

Myriam também esboça como um rascunho, no Caderno de 1980 a 1982, a ideia de uma escola de arte infantil, a qual fica entre pontos de interrogação, refletindo 
um "como fazer?" Estas reflexões e esta pergunta percebo que estão presentes nestes registros escritos de Myriam Anselmo, assim como estes esboços foram a base para um curso oferecido a um grupo de professoras da rede estadual de ensino de setembro a dezembro 1982, que teve a participação de vários professores ${ }^{6}$ e alunos do Instituto de Letras e Artes, os quais estavam sempre presentes nas atividades de ensino e de extensão de modo interdisciplinar (com as áreas de música, teatro, artes visuais).

Um dos professores do atual Centro de Artes, José Luiz Pellegrin - que foi aluno de Myriam e que participou ministrando aulas neste curso de 1982 - faz o relato desse envolvimento com as atividades, desde as aulas até os cursos de extensão, e percebo que estes eventos são promotores desta formação continuada, e transformadores de metodologias de ensino, na medida em que este envolvimento com a comunidade e com professores da rede de ensino provocava também que os formadores estivessem em permanente processo de criar novos caminhos para o ensino. Marie Christine Josso relaciona a formação com as experiências, a partir das quais as identidades e nossa subjetividade se constituem e se transformam.

\begin{abstract}
Dado que todo e qualquer objeto teórico se constrói graças à especificidade da sua metodologia, o mesmo também se passa com o conceito de formação, que se enriquece com práticas biográficas, ao longo das quais esse objeto é pensado, tanto como uma história singular, quanto como manifestação de um ser humano que objetiva as suas capacidades autopoiéticas (...) Formar-se é integrar numa prática o saber-fazer e os conhecimentos, na pluralidade de registros. (JOSSO, 2010, p. 35)
\end{abstract}

E como Fernando Hernández (2007) diz, é no cotidiano que precisamos ser catadores de novos sentidos, de novos caminhos para significar em arte. Do mesmo modo, percebo que o professor Pellegrin teve nas aulas com Myriam um ambiente de formação criativo e criador de pensamentos e de fluir da arte. Do legado de Myriam Anselmo, nas propostas tanto de aulas como de cursos de extensão, é possível

6 Participaram deste Curso cerca de 80 professores da rede estadual de ensino de 1 a 4 série do Ensino Fundamental. As aulas foram ministradas por Myriam Anselmo (Depto de Artes Visuais); José Luiz de Pellegrin (Depto de Artes Visuais); Cecy Bonat Hirsch (Depto de Música e Artes Cênicas) e Cândida Isabel Madruga da Rocha (Depto de Estudos da Arte, Letras e Comunicação), com coordenação da Profa. Angela Maria Sinotti Rocha Gonzales (Depto de Estudos da Arte, Letras e Comunicação). 
perceber uma visão de formação que relaciona o meio; o mercado de trabalho, as visualidades do cotidiano; as questões sociais e as demandas da arte.

\begin{abstract}
Esse olhar, que revisita o saber no circuito cultural e a respostas às demandas que o mercado impõe, era explorado como aplicação dos princípios que integravam o conteúdo das disciplinas e como modo de instaurar uma ética do trabalho que permitisse, a partir da experiência artística, instaurar um lugar para desenvolver habilidades e capacidades que pudessem refinar a percepção e educar os sentidos. O germe da inclusão social sempre permeou essa orientação que presume o fazer e o saber enquanto marcos de um sistema que valoriza a memória, os afetos, os cuidados e a potência da realização. Revela também um repertório e um saber do professor que é da ordem da vivência, aqui vivência como experiência. Um saber que se constitui enquanto realiza e repete o fazer, e faz tanto, que se diferencia pela repetição. Esse viés da inclusão definiu com o tempo o perfil extensionista, que caracteriza até hoje a área de arte. (PELLEGRIN, 2015)
\end{abstract}

Concordo com Josso que a abordagem biográfica pode ser um bom lugar para perceber aspectos relevantes das situações educativas, para ela "a experiência formadora é uma aprendizagem que articula, hierarquicamente: o saber-fazer e os conhecimentos, funcionalidade e significação, técnicas e valores num espaço-tempo que oferece a cada um a oportunidade de uma presença para si e para a situação" (2010, p. 36). E, nesse sentido, podemos verificar que a experiência e as práticas de ensino pelas quais passamos, são tão formadoras quanto o conteúdo formal das disciplinas. A vivência de um cotidiano que proporcione o questionamento constante do "como fazer?" é desafiador, pois, ao darmos uma resposta, não percebemos, mas uma transformação aconteceu.

\begin{abstract}
A experiência de ensinar e aprender se regia por uma espécie de compreensão e certeza de que o lugar de trabalho deverá ter características de acolhimento. $O$ espaço de trabalho se ordena pelo cuidado com os materiais, com a adequação ou apropriação dos instrumentos e a exploração da linguagem se dá pela singularidade da solução que a própria experiência incita. (...) A cada aula as motivações eram diferenciadas e os espaços poderiam ser ampliados; do espaço formal para a rua; da reconfiguração do espaço formal para a simulação de um espaço de trabalho que fosse representativo para o grupo ou para possíveis profissões, em que o exercício de relações sociais e de saberes pudessem ser praticados: da feira ao protesto na rua. (...) Traziam implicados nessa vivência a memória afetiva, o domínio técnico, a capacidade expressiva, a experiência social e a fluência para agir e reagir às novas circunstâncias por cada integrante. (PELLEGRIN, 2015)
\end{abstract}

Assim, ao realizar esses encontros com pessoas e com seus textos, reveladores de um tempo enriquecedor de vida como formadores, espero poder registrar algo do que foi a vida e o ensino das artes deste Centro de Artes, desde as 
suas origens, principalmente por meio dos rastros destes professores que deixaram sua marca, seus sonhos, seus afetos e realizaram obras, proporcionaram grandes momentos de ensino, de testemunho de vida, de dedicação à instituição acadêmica e inventaram um cotidiano múltiplo de visualidades, com o qual nos comprometemos a dar continuidade.

\section{Referências}

ARQUIVO DO CENTRO DE ARTES. UFPel, Pelotas.

BARBOSA, Ana Mae. História da Arte-Educação. São Paulo: Max Limonad, 1986.

BARBOSA, Ana Mae. A imagem do ensino da arte: anos oitenta e novos tempos. São Paulo: Perspectiva, 1991.

BERGSON, Henri. Memória e vida. São Paulo: Martins Fontes, 2006.

BIASOLI, Carmen Lúcia Abadie. A formação do professor de arte: do ensaio ... à encenação. 3. ed. São Paulo: Papirus, 2007.

BOURDIEU, Pierre. Homo academicus. Florianópolis: Editora da UFSC, 2013.

CADERNO DE ANOTAÇÕES DE MYRIAM ANSELMO - nov./1980 a dez./1982.

CADERNO DE ANOTAÇÕES DE MYRIAM ANSELMO - 1983

FRANCO, Janice Pires Corrêa. Memória de Marina. Pelotas: Editora Livraria Mundial, 2008.

HERNÁNDEZ, Fernando. Catadores da cultura visual. Porto Alegre: Mediação, 2007.

JOSSO, Marie-Christine. Experiências de vida e formação. Coleção Pesquisa AutoBiográfica: Paulus/EDUFRN, 2010.

LIPMAN, Matthew. A filosofia vai à escola. São Paulo: Summus, 1990.

PELLEGRIN, José Luiz de. Relato. Texto digital, não publicado, maio de 2015.

SILVA, Ursula R. da; LORETO, Mari-Lúcie. História da arte em Pelotas: a pintura de 1870 a 1980. Pelotas: EDUCAT, 1996.

\section{Ursula Rosa da Silva}

Possui Licenciatura Plena em Filosofia pela Universidade de Caxias do Sul (1988), Mestrado em Filosofia pela Pontifícia Universidade Católica do Rio Grande do Sul (1992), Doutorado em História pela Pontifícia Universidade Católica do Rio Grande do Sul (2002) e Doutorado em Educação (UFPel/2009). Professora Associada na Universidade Federal de Pelotas, desde 1995. Diretora do Centro de Artes da UFPel, desde 2013. É professora do Programa de Pós-Graduação (Mestrado) em Artes Visuais (PPGAV-UFPel), do qual é coordenadora adjunta, atuando na linha de Ensino da Arte e Educação Estética.

E-mail: ursularsilva@gmail.com

Currículos: http://lattes.cnpq.br/2360365860775097

Recebido em 30 de março de 2016

Aceito em 17 de julho de 2016 